\title{
Bacteroidales ectosymbionts of gut flagellates shape the nitrogen-fixing community in dry-wood termites
}

\author{
Mahesh S Desai ${ }^{1}$ and Andreas Brune \\ Department of Biogeochemistry, Max Planck Institute for Terrestrial Microbiology, Marburg, Germany
}

\begin{abstract}
Although it is well documented that the lack of nitrogen in the diet of wood-feeding termites is compensated by the nitrogen-fixing capacity of their gut microbiota, the bacteria responsible for this activity are largely unknown. Here, we analyzed the diversity and expression of nitrogenase genes (homologs of nifH) in four species of dry-wood termites (Kalotermitidae), which thrive on a particularly nitrogen-poor resource. Although each species harbored a highly diverse suite of termite-specific homologs in their microliter-sized hindgut, only a core set related to nifH genes of Treponema and Azoarcus spp., 'Azobacteroides pseudotrichonymphae', the first member of the Bacteroidales identified as a diazotroph, and termite-gut-specific anfH genes of hitherto unknown origin were preferentially expressed. Transcription patterns corroborated that the populations of active diazotrophs differ fundamentally between termite genera. Capillary-picked suspensions of the flagellates Devescovina arta and Snyderella tabogae revealed that their bacterial ectosymbionts each possess two paralogs of $\mathbf{n i f H}$, which apparently have been acquired consecutively during evolution of Bacteroidales, but only one of them (anfH) is actively expressed. Transcription patterns correlated neither with the molybdenum content of the diet nor with intestinal hydrogen concentrations, measured with microsensors. We propose that the nitrogen-fixing community in different dry-wood termites is shaped by the symbionts of their specific flagellate populations. Our findings suggest that the diazotrophic nature of 'Armantifilum devescovinae' has an important role in the nitrogen metabolism of dry-wood termites and is the driving force of co-evolution with its flagellate host.
\end{abstract}

The ISME Journal (2012) 6, 1302-1313; doi:10.1038/ismej.2011.194; published online 22 December 2011 Subject Category: microbe-microbe and microbe host-interactions

Keywords: nitrogen fixation; termite gut; flagellates; ectosymbionts; bacteroidales; alternative nitrogenase

\section{Introduction}

The hindguts of lower termites are microliter-sized bioreactors that convert lignocellulose to shortchain fatty acids with the help of symbiotic bacteria and flagellate protists (Breznak, 2000; Brune and Ohkuma, 2011). In view of the extremely low nitrogen content of wood $(<0.05 \%$ dry weight), Cleveland had suggested already almost a century ago that the severe nitrogen limitation in the diet of termites may be compensated by a nitrogen-fixing capacity of their gut microbiota (Cleveland, 1925). Nitrogen fixation in termite guts was eventually demonstrated in the 1970s (Benemann, 1973;

Correspondence: A Brune, Department of Biogeochemistry, Max Planck Institute for Terrestrial Microbiology, Karl-vonFrisch-Strasse 10, Marburg 35043, Germany.

E-mail: brune@mpi-marburg.mpg.de

${ }^{1}$ Current address: Courant Research Centre Geobiology, Georg-August-Universität Göttingen, Goldschmidtstrasse 3, Göttingen 37077, Germany.

Received 5 July 2011; revised 14 November 2011; accepted 18 November 2011; published online 22 December 2011
Breznak et al., 1973), and subsequent studies revealed that termites thriving on sound wood obtain $30-50 \%$ of the nitrogen in their colonies through this pathway (Tayasu et al., 1998).

Numerous nitrogen-fixing bacteria (diazotrophs) have been isolated from termite guts, but with the exception of spirochetes (Lilburn et al., 2001), none of the isolates is abundant enough to account for the nitrogen-fixing activities in the hindgut (for reviews, see Breznak, 2000; Brune, 2006). This view is supported by a number of cultivation-independent studies that characterized the homologs of the nifH gene present in termite guts (Ohkuma et al., 1996, 1999; Noda et al., 1999, 2002; Lilburn et al., 2001; Yamada et al., 2007), a well-conserved marker of diazotrophy (Zehr et al., 2003). A lack of congruence between the nifH genes of the isolates and the nifH homologs retrieved from the same environments indicates that the predominant diazotrophs in termite guts remain uncultivated (Brune and Ohkuma, 2011).

The nifH-like sequences in termite guts represent numerous novel and highly diverse lineages in all 
clusters (I-IV; nomenclature of Zehr et al., 2003) of nifH homologs. Many of the sequences in clusters II and III are closely related to nifH homologs of cultured Treponema species from the gut of Zootermopsis spp. (Lilburn et al., 2001; Graber et al., 2004), which suggests that the abundant termite gut spirochetes comprise many potential diazotrophs. This is supported by a metagenomic analysis of the hindgut community of a Nasutitermes species, where phylogenetic binning of nitrogenase genes implicated members of Spirochaetes and Fibrobacteres as the predominant microorganisms capable of $\mathrm{N}_{2}$ fixation (Warnecke et al., 2007). Other sequences in Cluster III are closely affiliated with nifH homologs of cellulolytic clostridia, which indicates that also uncultivated Firmicutes may be involved in this process (for details, see Ohkuma et al., 1999; Yamada et al., 2007).

However, not all of the diverse nitrogenase genes present among the gut microbiota seem to be expressed. Using the presence of nifH mRNA as an indicator of nifH gene expression and diazotrophic activity, Noda et al. (1999) demonstrated that the most highly expressed nitrogenases in the dry-wood termite Neotermes koshunensis (Kalotermitidae) were so-called alternative nitrogenases (anf) in Cluster II, paralogs of classical nitrogenases (nif) that contain neither molybdenum nor vanadium cofactors (Eady, 1996; Sicking et al., 2005). Closely related anfH genes are present also in Cryptotermes domesticus and Glyptotermes fuscus (Ohkuma et al., 1999; Yamada et al., 2007), but the general pattern of anfH expression in Kalotermitidae and the identity of the bacterium carrying these genes remain unknown.

The bulk of the hindgut volume in all lower termites is occupied by cellulolytic flagellatesstrictly anaerobic protists that are densely colonized by diverse bacterial symbionts (for reviews, see Hongoh and Ohkuma, 2010; Ohkuma and Brune, 2011). Although the flagellate symbionts can represent the vast majority of the bacteria in the hindgut, their contribution to the metabolic processes had long been completely unknown (Brune and Stingl, 2005; Brune and Ohkuma, 2011). Recently, Hongoh et al. (2008b) demonstrated that the genome of 'Candidatus Azobacteroides pseudotrichonymphae', the endosymbiont of Pseudotrichonympha grassi of the subterranean termite Coptotermes formosanus (Rhinotermitidae), encodes a complete nifHDK operon and all other genes essential for $\mathrm{N}_{2}$ fixation. This was not only the first report of nitrogen fixation in the Bacteroidales, but also the first time that the bulk of nitrogen-fixing activity in a lower termite could be attributed to the symbionts of their gut flagellates.

As specific associations between gut flagellates and symbiotic Bacteroidales are common also in dry-wood termites (Noda et al., 2006; Desai et al., 2010; Strassert et al., 2010), it seemed possible that
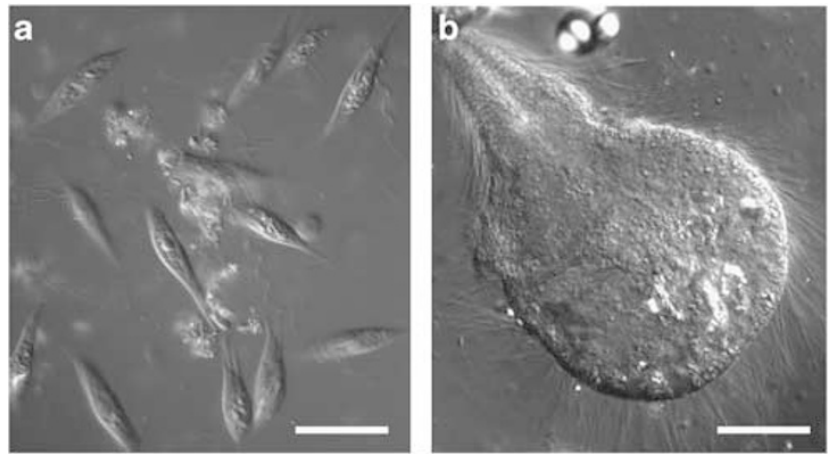

Figure 1 Differential interference contrast photomicrographs of the termite gut flagellates Devescovina arta (a) from Neotermes castaneus and Snyderella tabogae (b) from C. longicollis. Scale bars, $30 \mu \mathrm{m}$.

the high activities of nitrogen fixation present in this termite family are due to the symbiont of their flagellates. Here, we identified the active diazotrophs in representatives of four major genera of Kalotermitidae (Neotermes castaneus, Cryptotermes longicollis, Kalotermes flavicollis and Incisitermes marginipennis). We characterized the diversity of nifH genes and the actively transcribed homologs in the hindgut community by phylogenetic analysis of nifH clone libraries and fingerprinting analysis of the hindgut community. In addition, we investigated the identity and expression of nifH homologs associated with the bacterial symbionts of Devescovina arta and Snyderella tabogae (Figure 1), numerically predominant gut flagellates of the termite species $N$. castaneus and C. longicollis, in suspensions of capillary-picked flagellates. Finally, we used hydrogen microsensors to determine the hydrogen partial pressure in the gut of these dry-wood termites and investigated possible correlations of intestinal hydrogen concentration, molybdenum availability and nitrogen limitation with the transcription of specific nifH homologs.

\section{Materials and methods}

Termites and feeding trials

The four species of Kalotermitidae used in this study were obtained from the Federal Institute of Materials Research and Testing (BAM) (Berlin, Germany). Termites were maintained on a diet of pinewood in temperature- and humidity-controlled chambers $\left(25{ }^{\circ} \mathrm{C}, 72 \%\right.$ relative humidity). C. longicollis and I. marginipennis were kept exclusively on dry wood without any additional water, whereas $N$. castaneus and $K$. flavicollis were also provided with a layer of moist vermiculite. Prior to the acetylene reduction assay (see below), batches of termites (40-80 animals) were fed filter paper for 7-10 days. To test the effect of environmental factors on nifH transcription, smaller batches (15-20 animals) were placed on filter paper soaked with $\left(\mathrm{NH}_{4}\right)_{2} \mathrm{SO}_{4}(120 \mathrm{mM}), \mathrm{Na}_{2} \mathrm{MoO}_{4}(1 \mathrm{mM})$ or water for 
the same duration (Noda et al., 1999), or were incubated under an air headspace amended with $40 \% \mathrm{H}_{2}$. Pseudergates (worker larvae) were used for all experiments.

\section{Nucleic acid extraction}

Ten to 15 termites were dissected, and whole guts were immediately placed into an ice-cold solution of sodium phosphate $(0.1 \mathrm{M})$, Tris-HCl (125 mM), $\mathrm{NaCl}(25 \mathrm{mM})$ and sodium dodecyl sulfate $(2.5 \%$, $\mathrm{w} / \mathrm{v})(\mathrm{pH}$ 8.0), and homogenized by bead beating (Henckel et al., 1999). Total nucleic acids (DNA and RNA) were co-extracted with phenol-chloroformisoamyl alcohol and purified as described previously (Lueders et al., 2004). The nucleic acids of the flagellates $D$. arta from $N$. castaneus and S. tabogae from $C$. longicollis were extracted from capillarypicked flagellate suspensions (Desai et al., 2010). To test the effect of environmental conditions on nifH transcription, guts of all termites were prepared in the same manner, and total RNA was extracted using the Trizol method (Invitrogen, Karlsruhe, Germany). DNA extraction, PCR amplification, cloning and sequencing of small-subunit (SSU) rRNA genes of flagellates and their bacterial symbionts were performed as described previously (Desai et al., 2010). DNA and cDNA clone libraries (see below) were obtained from the same nucleic acid preparations, and flagellate suspensions were prepared from the same batch of termites.

\section{PCR, RT-PCR and cloning of nifH homologs}

The nifH homologs were amplified from total nucleic acids using universal nifH primers (IGK and YAA), recombinant TaqDNA polymerase (Invitrogen) and the PCR conditions described by Ohkuma et al. (1999). When DNA from gut homogenates was used as a template, $0.4 \mathrm{mg} \mathrm{ml}^{-1}$ bovine serum albumin was included in the reaction mixture.

For reverse transcription (RT)-PCR, nucleic acid extracts were digested with RNase-free DNase (RQ1; Promega, Mannheim, Germany) and subjected to a single-tube, one-step, two-enzyme RT-PCR (Access RT-PCR System kit; Promega) using the primers IGK and YAA, including $0.4 \mathrm{mg} \mathrm{ml}^{-1}$ bovine serum albumin, and following the manufacturer's instructions. The RT-PCR program started with a reverse transcription step for $45 \mathrm{~min}$ at $48{ }^{\circ} \mathrm{C}$, immediately followed by an initial denaturation step at $94^{\circ} \mathrm{C}$ for $2 \mathrm{~min}$, and a total of 30 cycles (denaturation at $94{ }^{\circ} \mathrm{C}$ for $30 \mathrm{~s}$, extension at $68^{\circ} \mathrm{C}$ for $2 \mathrm{~min}$ ). The first nine cycles were operated with a touchdown program (annealing at $57^{\circ} \mathrm{C}$ for $45 \mathrm{~s}$, decreasing $1^{\circ} \mathrm{C}$ per cycle); the remaining cycles had an annealing temperature of $48{ }^{\circ} \mathrm{C}$. Final extension was at $68^{\circ} \mathrm{C}$ for $10 \mathrm{~min}$. Specificity of the RT-PCR was validated by standard agarose gel electrophoresis. Parallel assays without reverse transcriptase did not yield any product, confirming the absence of DNA template in the RNA samples.
Amplicons were cloned with the pGEM-T easy cloning kit (Promega) according to the manufacturer's instructions. Inserts were commercially sequenced using M13 primers (GATC, Konstanz, Germany). Nucleic acid sequences have been submitted to the EMBL/GenBank database under accession numbers FN649270-FN649328, FN649412 and FN649413.

\section{Phylogenetic analysis}

The SSU rRNA genes of flagellates and bacteria were phylogenetically analyzed as described previously (Desai et al., 2010). For phylogenetic analysis of nifH homologs, we built a comprehensive database including representatives of all established lineages (Zehr et al., 2003) and all sequences previously obtained from termite guts (Yamada et al., 2007), using the ARB software suite (http://www. arb-home.de). Novel sequences were aligned both at the nucleotide and the amino-acid level. Phylogenetic trees (amino-acid alignments) were constructed using the maximum-likelihood algorithm implemented in ARB (PhyML with Dayhoff PAM, 100 bootstraps); tree topology was confirmed with maximum-parsimony analysis (PHYLIP Protein parsimony; 1000 bootstraps).

\section{T-RFLP analysis}

The PCR and RT-PCR conditions were the same as described above, except that the forward primer (IGK) was fluorescence-labeled with pentamethine carbocyanine (IRD 700; MWG Biotech, Ebersberg, Germany). Amplicons were digested with the restriction enzyme HhaI (Promega), and terminal restriction fragment (T-RF) length polymorphism (T-RFLP) was analyzed as described previously (Pester and Brune, 2006). T-RF length was calculated by comparison with molecular size markers (50-700 bp, LI-COR) using the Gel-Pro Analyzer software (version 4.5; Media Cybernetics, Bethesda, MD, USA).

\section{Hydrogen microsensor measurements}

Polarographic hydrogen microsensors had a tip diameter of $10 \mu \mathrm{m}$ and were purchased from Unisense (Aarhus, Denmark). Microsensor calibration and the experimental setup for hydrogen measurement in termite guts have been described in detail elsewhere (Ebert and Brune, 1997; Pester and Brune, 2007).

\section{Acetylene reduction assay}

Nitrogenase activity in living termites was determined using rubber-stoppered glass vials $(10 \mathrm{ml})$ containing 40-90 termites under air amended with $16 \%$ acetylene at $30^{\circ} \mathrm{C}$ (Breznak et al., 1973; Noda et al., 1999). Samples $(0.1 \mathrm{ml})$ of headspace gas were analyzed for ethylene by gas chromatography over several hours. The gas chromatograph (GC 14b; Shimadzu, Griesheim, Germany) was equipped with a stainless-steel column filled with Porapak R 
(Macherey-Nagel, Darmstadt, Germany; 80/100 mesh, $\left.6^{\prime} \times 1 / 8^{\prime \prime}\right)$ and a flame ionization detector, using nitrogen as carrier gas and isothermal conditions $\left(40^{\circ} \mathrm{C}\right)$.

\section{Results}

PCR of total nucleic acids from the guts of the four termite species using nifH-specific primers yielded products of the expected length ( $\sim 470 \mathrm{bp})$. Amplicons of the same length were obtained also by RT-PCR of total RNA in DNase-treated extracts, and by PCR of DNA extracted from capillary-picked flagellate suspensions of $D$. arta and S. tabogae from the termite species $N$. castaneus and $C$. longicollis. Clone libraries were constructed for each sample, and the sequences of the nifH homologs in the libraries were compared (Table 1).
Diversity of nifH homologs in gut homogenates

The clone libraries revealed a high diversity of nifH homologs in the hindguts of the four termite species. Alignment of the sequences showed that each termite species harbored numerous phylotypes that clustered with the sequences of other nifH homologs previously obtained from termite guts. We extended the nomenclature of Yamada et al. (2007) to indicate their phylogenetic affiliation (Figure 2). Clones sharing the same amino-acid signature were considered as one phylotype. Many phylotypes obtained from several or all of the termite species were highly similar, but members of each cluster had a characteristic amino-acid signature and differed considerably in their DNA sequence. The amino-acid sequences of all nifH homologs (groups I-III) showed the four cysteine and one arginine residues typically conserved in proteins of the NifH family (Dean and Jacobson, 1992). A few

Table 1 Phylotypes of nifH homologs obtained from hindgut homogenates of the four termite species and from flagellate suspensions of Devescovina arta (from N. castaneus) and Snyderella tabogae (from C. longicollis)

\begin{tabular}{|c|c|c|c|c|c|c|c|}
\hline \multirow[t]{2}{*}{ Termite } & \multirow[t]{2}{*}{ Phylotypes ${ }^{\text {a }}$} & \multirow[t]{2}{*}{ Phylogenetic group ${ }^{\mathrm{b}}$} & \multicolumn{3}{|c|}{ Number of clones/library } & \multirow[t]{2}{*}{ Genotypes ${ }^{\mathrm{c}}$} & \multirow[t]{2}{*}{ T-RF length $(b p)^{\mathrm{d}}$} \\
\hline & & & $D N A$ & $c D N A$ & $\begin{array}{c}\text { Flagellates } \\
(D N A)\end{array}$ & & \\
\hline \multicolumn{8}{|c|}{ Neotermes castaneus } \\
\hline & Aarc-1 & Azoarcus-related (I) & $0 / 23$ & $1 / 12$ & $0 / 7$ & FN649278 & 58 \\
\hline & Arma-1 & Armantifilum (II) & $0 / 23$ & $8 / 12$ & $4 / 7$ & FN649273-74 & 171 \\
\hline & Bact-1a, b & Bacteroidales (III-3a) & $2 / 23$ & $2 / 12$ & $3 / 7$ & FN649270-72 & 120, 142, 269 \\
\hline & Trepo-1a, b & Treponema (III-3b) & $6 / 23$ & $0 / 12$ & $0 / 7$ & FN649275-77 & 142 \\
\hline & Firmi-1 & Subgroup III-1b & $2 / 23$ & $1 / 12$ & $0 / 7$ & FN649283-84 & 190, 269 \\
\hline & Others & Group II & $13 / 23$ & $0 / 12$ & $0 / 7$ & FN649279, 88, 89 & $323,171,182$ \\
\hline & & Subgroup III-1a & & & & FN649280, 82 & 470,142 \\
\hline & & Subgroup III-2 & & & & FN649281, 85 & 168,142 \\
\hline & & Group IV & & & & FN649286, 87 & 53 \\
\hline \multicolumn{8}{|c|}{ Cryptotermes longicollis } \\
\hline & Arma-2a, b & Armantifilum (II) & $14 / 20$ & $10 / 10$ & $7 / 12$ & FN649293-97 & 171 \\
\hline & Bact-2, 1c & Bacteroidales (III-3a) & $3 / 20$ & $0 / 10$ & $5 / 12$ & FN649290-92 & 120,168 \\
\hline & Trepo-2 & Treponema (III-3b) & $2 / 20$ & $0 / 10$ & $0 / 12$ & FN649298 & 317 \\
\hline & Firmi-2 & Subgroup III-1b & $1 / 20$ & $0 / 10$ & $0 / 12$ & FN649299 & 269 \\
\hline \multicolumn{8}{|c|}{ Kalotermes flavicollis } \\
\hline & Arma-3 & Armantifilum (II) & $1 / 21$ & $0 / 18$ & & FN649312 & 182 \\
\hline & Bact-3, 4a, b & Bacteroidales (III-3a) & $9 / 21$ & $17 / 18$ & & FN649300-11 & 120, 142, 168, 415 \\
\hline & Trepo-3 & Treponema (III-3b) & $6 / 21$ & $1 / 18$ & & FN649313-14 & 228 \\
\hline & Firmi-3 & Subgroup III-1b & $1 / 21$ & $0 / 18$ & & FN649318 & 317 \\
\hline & Others & Group II & $4 / 21$ & $0 / 18$ & & FN649315 & 275 \\
\hline & & Subgroup III-2 & & & & FN649316-17 & 142 \\
\hline & & Group IV & & & & FN649319 & 53 \\
\hline \multicolumn{8}{|c|}{ Incisitermes marginipennis } \\
\hline & Aarc-2 & Azoarcus-related (I) & $2 / 22$ & $3 / 10$ & & FN649326 & 142 \\
\hline & Trepo-4 & Treponema (III-3b) & $10 / 22$ & $7 / 10$ & & FN649320-25 & 269 \\
\hline & Firmi-4 & Subgroup III-1b & $9 / 22$ & $0 / 10$ & & FN649328 & 269 \\
\hline & Others & Group IV ${ }^{\mathrm{e}}$ & $1 / 22$ & $0 / 10$ & & FN649327 & 269 \\
\hline
\end{tabular}

Abbreviation: T-RF, terminal restriction fragment.

The abundance of clones in the respective clone libraries (DNA or cDNA) is given for each phylotype, together with the representative genotypes and corresponding T-RFs.

aThe phylotypes (clones sharing the same amino acid signature) within each group were typically quite similar (96-99\% amino-acid identity; details not shown).

${ }^{\mathrm{b}}$ The phylogenetic position of the groups is shown in Figure 2.

${ }^{c}$ Representative sequences were selected for each phylotype. They typically had more than 99\% DNA sequence similarity.

dT-RFs of clones from the cDNA libraries are shown in bold (see Figure 4).

eSequences in Group IV (pseudo-nifH) were not included in Figure 2. 


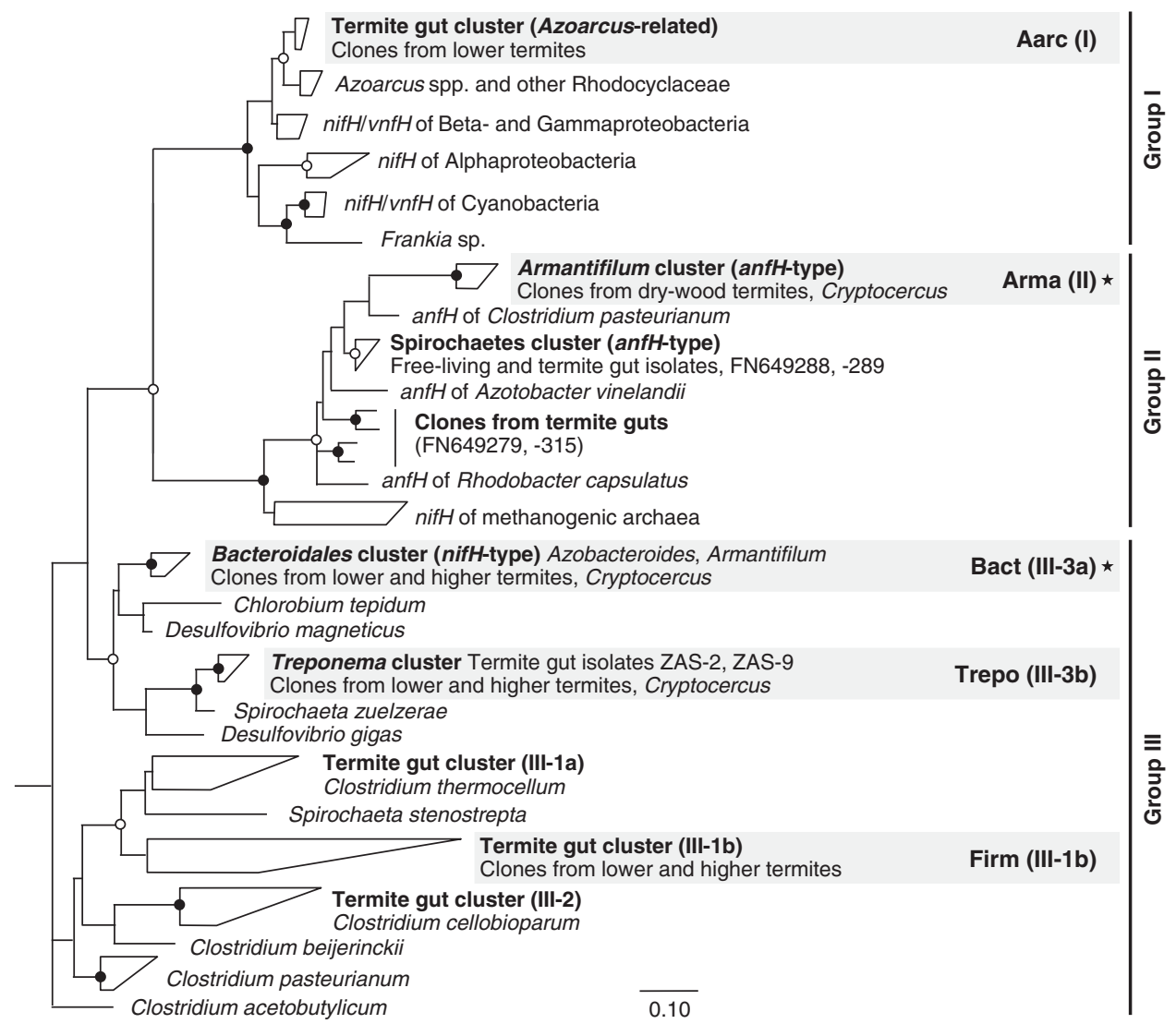

Figure 2 A maximum-likelihood tree showing the phylogenetic relationship of nifH homologs obtained from dry-wood termites to those of other termites and representative isolates. Group nomenclature is based on Yamada et al. (2007). Clusters containing sequences obtained in this study are shown in bold; the shaded clusters contain sequences of genes that are preferentially expressed (see Table 1 for details). The marked clusters $\left({ }^{*}\right)$ contain nifH homologs from flagellate suspensions (for details, see Figure 3). The tree was rooted using Group-IV (pseudo nifH) genes as outgroup. Tree topology is based on maximum-likelihood analysis of 144 unambiguously aligned amino-acid positions and was confirmed by maximum-parsimony analysis; nodes with high bootstrap support are marked $(\bigcirc>70 \% ; \bullet>90 \%)$.

sequences fell into the so-called pseudo-nif group (Group IV; Ohkuma et al., 1999) and are not explicitly shown in the tree (for details, see Table 1).

Sequences in Group-I were relatively rare and were found only in N. castaneus and I. marginipennis, where they formed a termite-specific cluster (Aarc) comprising a previously published nifH homolog from Reticulitermes speratus (Rs17; Ohkuma et al., 1996). They were most closely related to the nifH gene of Azoarcus strain BH72 (92.3-93.0\% amino-acid identity).

Group II was mostly represented by a cluster of closely related clones (Arma) encountered in three of the four termites species (not in I. marginipennis) (Figure 3). They are most closely related to the anfH gene of Clostridium pasteurianum (80.9-82.3\% amino-acid identity). Sequences in this cluster had been previously recovered only from the dry-wood termites $N$. koshunensis and C. domesticus, and the wood-feeding cockroach Cryptocercus punctulatus (Yamada et al., 2007). The homolog from $N$. koshunensis is part of an operon encoding an alternative nitrogenase (Anf) lacking an Mo cofactor
(Noda et al., 1999). A few other clones were closely related to the anfH genes of Spirochaetes (including an isolate from the termite gut; Lilburn et al., 2001) and Rhodobacter capsulatus.

Sequences from Group III were quite diverse and fell mostly into subgroup III-3. A large number of clones clustered with the nifH gene of ' $A$. pseudotrichonymphae' (93.7-97.8\% amino-acid identity), the first member of the Bacteroidales identified as a diazotroph (Figure 3; Hongoh et al., 2008b). Clones from this cluster (Bact) were retrieved from the same three termites as those from Group II (Arma), but in contrast to the latter, also comprised many nifH homologs previously obtained from other termite families (Yamada et al., 2007). A second cluster (Trepo) of clones was most closely related to a nifH homolog of the termite gut spirochete Treponema azotonutricium (97.2-98.6\% amino-acid identity) and was represented in all four termite species. Three of the four termite species (not $C$. longicollis) also harbored clones from subgroups III-1 and III-2, which have been previously detected in termites of diverse families (Yamada et al., 2007) and are related to the nifH homologs of Clostridiales. 


\section{Arma (II)}

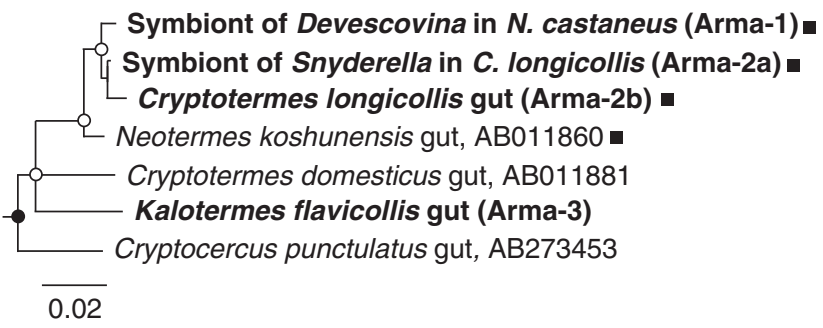

Bact (III-3a)

Symbiont of Devescovina in N. castaneus (Bact-1a)

o- Cryptotermes domesticus gut, AB011895

Cryptotermes longicollis gut (Bact-1c)

- Neotermes castaneus gut (Bact-1b)

Glyptotermes fuscus gut, AB011908

Pericapritermes nitobei gut, AB011961

- Symbiont of Snyderella in C. longicollis (Bact-2)

Neotermes koshunensis gut, AB027749

Coptotermes gestroi gut, AB273323

Cand. Azobacteroides from C. formosanus, NC011565

- Kalotermes flavicollis gut (Bact-3) .

- Kalotermes flavicollis gut (Bact-4a) - Schedorhinotermes medioobscurus gut, AB273344

- Zootermopsis nevadensis gut, AB273367

- Kalotermes flavicollis gut (Bact-4b)

- Schedorhinotermes medioobscurus gut, AB273345

- Mastotermes darwiniensis gut, AB273399

- Zootermopsis nevadensis gut, AB273381

- Cryptocercus punctulatus gut, AB273418

0.02

Figure 3 Consensus trees showing the phylogenetic relationship of nifH homologs in the clusters Arma (II) and Bact (III-3a) containing sequences obtained from flagellate suspensions of Devescovina and Snyderella spp. Sequences obtained in this study are shown in bold; phylotypes represented also in cDNA libraries are marked ( $\mathbf{\square}$; see Table 1 for details). The trees were rooted using the next relatives as outgroup (see Figure 2). Tree topology was confirmed by maximum-parsimony analysis; nodes with high bootstrap support are marked $(\bigcirc>50 \%$; $>90 \%)$.

The phylotypes in the mRNA-based clone libraries were typically found also in the DNAbased libraries of the same nucleic acid preparations, but the diversity of the cDNA clones seemed to be lower. Many phylotypes were not represented (Table 1), which indicated that not all nifH homologs present in the respective gut communities may be transcribed. Nevertheless, the clusters Aarc, Arma, Bact, Firmi and Trepo were present in the cDNA libraries of several or all termite species inspected (see Table 1). The Bact cluster consisted of multiple phylotypes in all termites except $I$. marginipennis, but only Bact-1a (N. castaneus) and Bact-3 (K. flavicollis) seem to be expressed. The PCR conditions were highly specific for nifH homologs; only the cDNA library of $N$. castaneus yielded an additional, non-nifH sequence (homologous to a putative ribonucleoside reductase transcript from human feces) that was also represented in the corresponding T-RFLP profile (labeled non-nifH in Figure 4).

nifH homologs in capillary-picked flagellates

Cloning and sequence analysis of the eukaryotic SSU rRNA genes in the capillary-picked suspensions of $D$. arta and $S$. tabogae confirmed the purity of the preparations. The sequence of $D$. arta was identical to that obtained in a previous study of the same termite (FN377761; Desai et al., 2010); the newly obtained SSU rRNA gene sequence of $S$. tabogae has been submitted to GenBank (FN649413).

Analysis of the bacterial 16S rRNA gene sequences obtained from the same suspensions confirmed the association of $D$. arta with 'Candidatus Armantifilum devescovinae' and an 'Endomicrobium' species, the two previously reported symbionts of this flagellate (Desai et al., 2010). The bacterial clones from $S$. tabogae comprised only a single phylotype (FN649412) that was almost identical (99.0\% sequence similarity) to the previously reported ectosymbiont (CcSn-04; AB462747) of a Snyderella sp. from the termite Cryptotermes cavifrons (Noda et al., 2009). Both formed a sister group of 'A. devescovinae' in Cluster $\mathrm{V}$ of Bacteroidales (see below). Sequences of 'Endomicrobia' were not detected in $S$. tabogae.

The clone libraries of nifH genes obtained from the same suspensions each yielded two distinct phylotypes (Arma and Bact) in equal abundance. With both flagellates, the sequences were identical to that of the phylotypes obtained from the DNA-based and/or mRNA-based clone libraries of the respective whole-gut homogenates (Arma-1 and Bact-1a for D. arta; Arma-2a and Bact-2 for S. tabogae; Table 1).

Community profiles of nifH genes and mRNA

To corroborate the relative abundance of nifH genes and their transcripts in the hindgut communities, we also obtained DNA-based and mRNA-based T-RFLP profiles of the respective nucleic acid extracts (Figure 4). The results confirmed the high diversity of nifH genes among the gut microbiota and the preferential transcription of only a few homologs that was already observed with the clone libraries. Almost all of the peaks in the mRNA-based profiles could be assigned to a corresponding phylotype in the clone libraries, which indicated that the analysis accounted for the majority of the expressed nifH homologs. Although most of the phylotypes in the DNA-based clone libraries were represented also in the corresponding T-RFLP profiles, the presence of several additional peaks indicated that nifH gene diversity in the clone libraries had not been exhaustively sampled. Replications of the mRNA-based T-RFLP profiles with nucleic acids extracted from different batches 
DNA

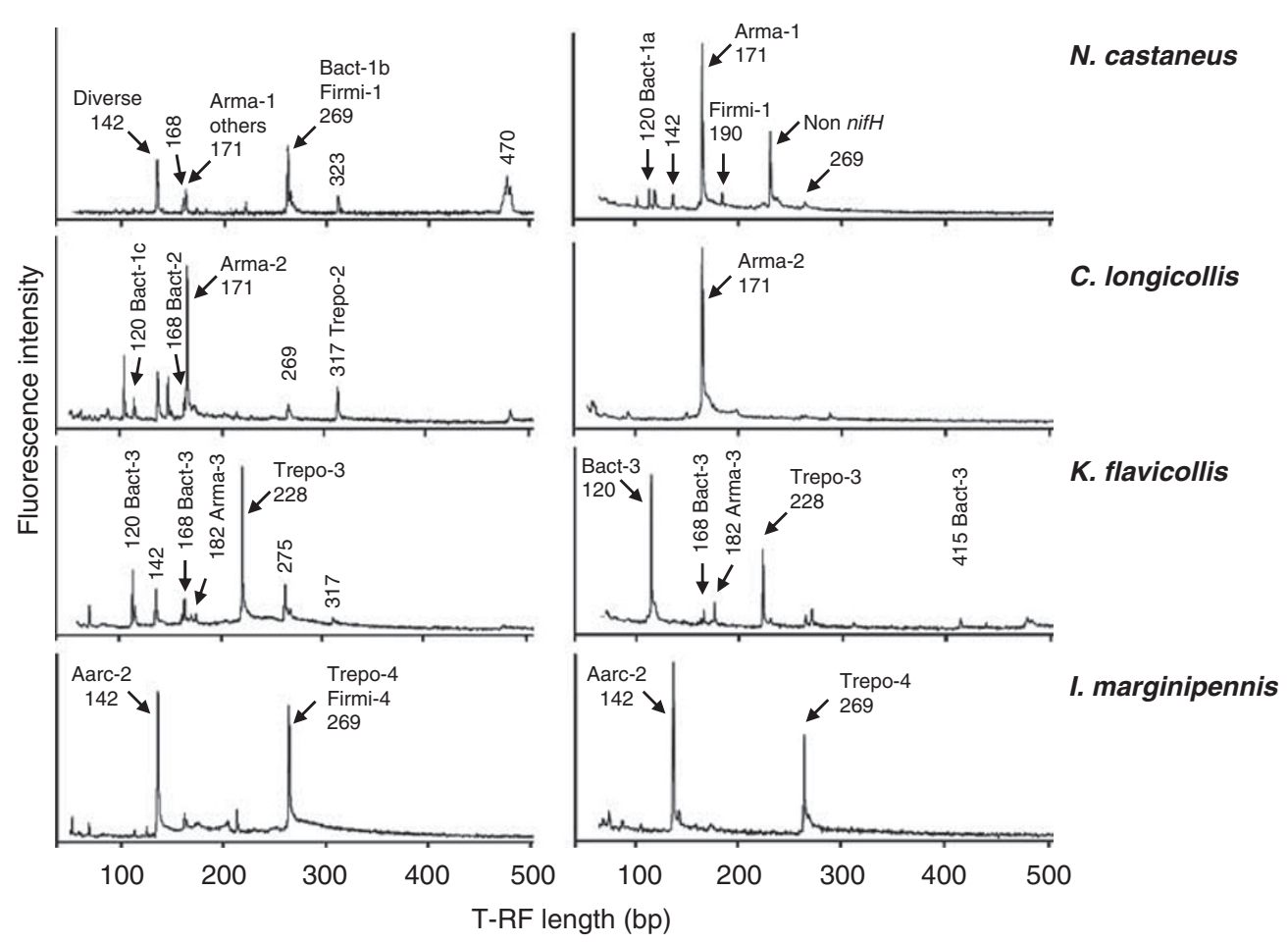

Figure 4 DNA- and mRNA-based T-RFLP profiles of nifH homologs from the hindgut of four termite species. PCR products ( $\sim 470$ bp) were digested with HhaI. Peak assignment is based on T-RF lengths of the nifH homologs obtained from the respective clone libraries (Table 1).

of $N$. castaneus, K. flavicollis and C. longicollis (I. marginipennis was no longer available at this point) yielded almost identical profiles for the respective species (data not shown).

An effect of the slight changes in the protocol used for RT-PCR on the comparison of DNA-based and mRNA-based T-RFLP profiles was not observed. When the nucleic acids extract of $N$. castaneus was subjected to the same protocol as used for RT-PCR except that no reverse transcriptase was added, T-RFLP analysis of the PCR product yielded a T-RFLP profile identical to that of the standard protocol, indicating that inclusion of bovine serum albumin, the different polymerase in the RT-PCR kit and the touchdown protocol did not affect the results. As this control was not conducted for all samples, we cannot exclude with certainty that minor differences between the DNAbased and mRNA-based profiles are caused by experimental bias.

Effect of environmental factors on nifH transcription To understand the effect of environmental factors on the transcription and expression of nifH homologs in the four termite species, we conducted several feeding trials with different diets. All termite species produced ethylene from acetylene, which indicated that nitrogenase is synthesized in all termites under normal (wood-feeding) conditions,
Table 2 Acetylene reduction rates of termites kept on a diet of wood or filter paper

\begin{tabular}{lcrrc}
\hline Termite & $\begin{array}{c}\text { Number } \\
\text { of } \\
\text { termites }\end{array}$ & $\begin{array}{c}\text { Average } \\
\text { weight } \\
(\mathrm{mg})^{\mathrm{a}}\end{array}$ & & \multicolumn{2}{c}{$\begin{array}{c}\text { Specific rate } \\
\left(\mathrm{nmolg}^{-1} \mathrm{~h}^{-1}\right)^{\mathrm{b}}\end{array}$} \\
\cline { 4 - 5 } & & & Wood & Filter paper \\
\hline Neotermes castaneus & 40 & 16.6 & $27.1 \pm 2.0$ & $39.7 \pm 2.1$ \\
Cryptotermes longicollis & 60 & 7.2 & $4.4 \pm 1.4$ & - $^{\mathrm{c}}$ \\
Kalotermes flavicollis & 80 & 7.2 & $4.6 \pm 0.2$ & $4.2 \pm 0.3$ \\
Incisitermes marginipennis & 80 & 27.2 & $18.3 \pm 2.7$ & $40.9 \pm 4.7$
\end{tabular}

a Fresh weight, determined with five randomly selected individuals. ${ }^{\mathrm{b}}$ Average of two replicates, determined over an interval of $1 \mathrm{~h}$ (I. marginipennis), $2 \mathrm{~h}$ (N. castaneus) or $3 \mathrm{~h}$ (C. longicollis, K. flavicollis). 'Not determined.

albeit at different levels (Table 2). With the exception of $K$. flavicollis, the nitrogenase activity of all species increased almost twofold when termites were fed filter paper for 7-10 days. When $N$. castaneus was fed filter paper soaked with ammonium sulfate solution, acetylene was no longer reduced.

Dietary effects on the preferential transcription of anfH genes in the gut of $N$. castaneus and C. longicollis were assessed by comparing the mRNA-based T-RFLP profiles under different feeding regimens. In $N$. castaneus, the T-RF corresponding to the anfH gene (171 bp) was always the largest peak, but an additional T-RF of $142 \mathrm{bp}$ (corresponding 
Table 3 Relative abundance of T-RFs in expression profiles of nifH homologs obtained from the guts of $N$. castaneus subjected to different feeding regimen and environmental conditions

\begin{tabular}{|c|c|c|c|c|c|}
\hline \multirow{2}{*}{$\begin{array}{l}\text { Feeding regimen } \\
\text { T-RF (bp) } \\
\text { Phylotype }\end{array}$} & \multicolumn{5}{|c|}{ Total peak height $(\%)^{\mathrm{a}}$} \\
\hline & $\begin{array}{c}120 \\
\text { Bact-1a }\end{array}$ & $\begin{array}{c}142 \\
\text { Multiple }\end{array}$ & $\begin{array}{c}171 \\
\text { Arma-1 }\end{array}$ & $\begin{array}{c}190 \\
\text { Firmi-1 }\end{array}$ & $\begin{array}{c}269 \\
\text { Unknown }\end{array}$ \\
\hline $\begin{array}{l}\text { Standard conditions } \\
\text { Dry wood only }^{\mathrm{c}} \\
\text { Filter paper } \\
+ \text { molybdate } \\
+\mathrm{molybdate}^{\mathrm{d}} \mathrm{H}_{2} \\
+\mathrm{H}_{2}\end{array}$ & $\begin{array}{l}6.0 \\
7.1\end{array}$ & $\begin{array}{r}7.6 \\
41.0 \\
43.3 \\
10.8 \\
2.9 \\
4.5\end{array}$ & $\begin{array}{l}77.3 \\
57.0 \\
56.7 \\
74.7 \\
90.0 \\
95.5\end{array}$ & 4.5 & $\begin{array}{l}2.3 \\
2.0\end{array}$ \\
\hline
\end{tabular}

Abbreviation: T-RF, terminal restriction fragment.

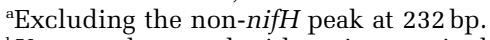

${ }^{\mathrm{b}}$ Kept on dry wood with moist vermiculite.

'Fed exclusively dry wood.

${ }^{\mathrm{d}}$ Filter paper soaked with sodium molybdate solution and/or termites incubated with $\mathrm{H}_{2}$.

to several nifH homologs from different groups; see Table 1) increased in relative abundance in termites fed a nitrogen-poor diet (filter paper or dry wood without vermiculite). However, the peak did not increase strongly if the filter paper was soaked with sodium molybdate solution, and disappeared almost completely when termites were incubated under $\mathrm{H}_{2}$ (Table 3). In C. longicollis, the T-RF corresponding to the anfH gene was the only peak under all treatments. All T-RFs (except the non-nifH peak in $N$. castaneus) disappeared from the mRNA-based profiles when $N$. castaneus and $C$. longicollis were fed filter paper soaked with ammonium sulfate solution.

Microsensor measurements of hydrogen partial pressure showed that only I. marginipennis and $K$. flavicollis accumulated hydrogen in the hindgut paunch (Figure 5). Highest hydrogen partial pressures were always encountered in the anterior region ( $K$. flavicollis, $32.4 \pm 12.3 \mathrm{kPa}, n=4$; I. marginipennis, $42.8 \pm 4 \mathrm{kPa}, n=3)$. In $N$. castaneus and C. longicollis, hydrogen did not accumulate above the detection limit of the sensors $(0.1 \mathrm{kPa})$. However, the preferential transcription of anfH genes remained unaffected when filter-paper-fed $N$. castaneus and $C$. longicollis were kept under a headspace supplemented with hydrogen gas for 2 days, both in the presence and in the absence of molybdate (Table 3).

\section{Discussion}

Our results document that the nitrogen-fixing populations among the bacterial gut microbiota of dry-wood termites (Kalotermitidae) differ between the four termite species investigated in this study. Although all species seem to harbor a similar set of diazotrophs in their hindgut, their nifH expression patterns are dominated by different phylogenetic groups. There is strong evidence that the anfH genes
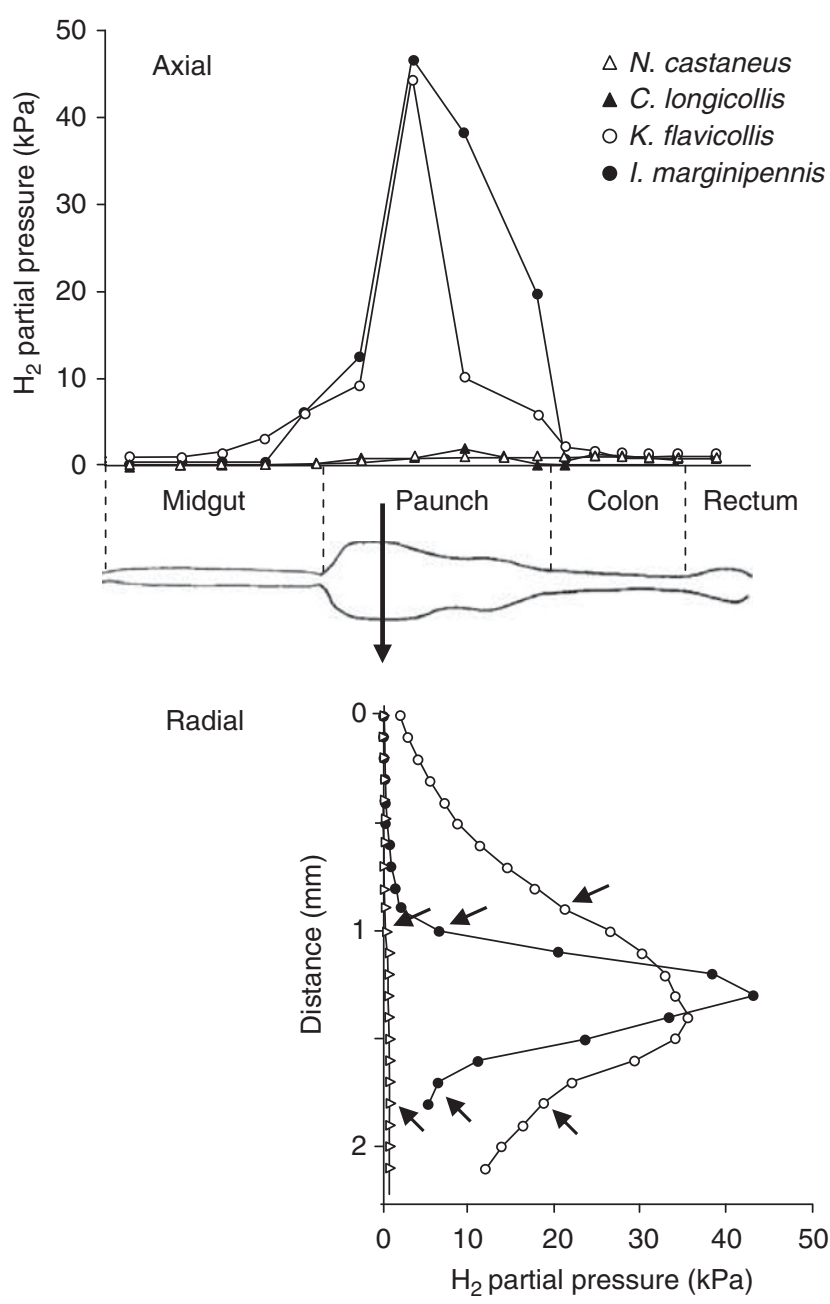

Figure 5 Profiles of hydrogen partial pressures in agaroseembedded guts of the four species of dry-wood termites, measured with microsensors. Axial profiles were normalized to account for different gut lengths. Radial profiles were taken from the agarose surface through the middle of the anterior hindgut paunch (indicated by the long arrow) for all termites except C. longicollis; the short arrowheads indicate the positions of the proximal and distal hindgut wall. Profiles were selected as typical from three to five replicates; values for the rectum may not be reliable because the content was often lost during dissection.

preferentially expressed in Neotermes species, as first reported by Noda et al. (1999) for N. koshunensis, belong to 'A devescovinae', the ectosymbiont of the most abundant gut flagellates of many dry-wood termites (Devescovina spp.; Desai et al., 2010). Also the nifH expression patterns in other dry-wood termites appear to be shaped by flagellate symbionts. After the report of nitrogen fixation in 'A. pseudotrichonymphae' (Hongoh et al., 2008b)the nitrogen-fixing endosymbionts of Pseudotrichonympha spp. from subterranean termites (Rhinotermitidae; Noda et al., 2007)-this is the second case of diazotrophy in the phylum Bacteroidetes. The apparently consecutive acquisition of two (nifH and anfH) paralogs during evolution may-as in the case of 'A. pseudotrichonymphae'-also serve 
to explain the strict co-speciation of 'A. devescovinae' with its flagellate host (Desai et al., 2010).

We were quite surprised to recover two nearly identical sets of nifH homologs from flagellate suspensions of $D$. arta and $S$. tabogae. The lack of any nitrogenase genes from 'Endomicrobium trichonymphae' (Hongoh et al., 2008a)—the closest relative of the second symbiont of $D$. arta (Desai et al., 2010)—and the apparent absence of 'Endomicrobia' from $S$. tabogae strongly suggest that both the Arma-1 (anfH) and the Bact-1a (nifH) paralogs stem from 'A. devescovinae' and the closely related symbiont of $S$. tabogae. The origin of both paralogs from the same population of symbionts is further supported by their almost equal abundance in the clone libraries of the respective flagellate suspensions.

The nifH homologs (Bact) obtained from 'A. devescovinae' and the symbiont of $S$. tabogae are closely related to the nifH gene of ' $A$. pseudotrichonymphae', which is an endosymbiont of a different flagellate lineage (Noda et al., 2007) and the first member of the Bacteroidales known to possess a nif operon, which must have been acquired by horizontal gene transfer from a diazotrophic member of another bacterial phylum (Hongoh et al., 2008b). As all three symbionts belong to the same termite-specific lineage of Bacteroidales (Cluster V; Ohkuma et al., 2002), it is possible that a nifH gene of subgroup IIIa was present already among the gut microbiota of the dictyopteran ancestor of termites and has been maintained throughout the lineage of Cluster-V Bacteroidales (Figure 6). This is supported by the presence of nifH subgroup III-3a in many termite species and also in their closest relative, the cockroach $C$. punctulatus (Yamada et al., 2007 and this study).

The anfH homolog (Arma), however, was probably acquired at a later time. This termite-specific lineage of anfH genes in Cluster II, originally discovered by Ohkuma et al. (1999), so far comprises only sequences from dry-wood termites and C. punctulatus (Yamada et al., 2007 and this study). Considering that ' $A$. devescovinae' and the symbionts of Snyderella spp. are sister groups, the most parsimonious explanation for the presence of two nifH paralogs in this apical lineage would be secondary acquisition of an anfH gene (Group II) in addition to the nifH gene (Cluster III-3a) already present in Cluster-V Bacteroidales (Figure 6). However, in the absence of direct evidence (that is, genome analysis or in situ hybridization), the possibility that the two nifH homologs originated from a minor bacterial population present in both suspensions cannot be eliminated completely.

The origin of the anfH genes in Neotermes and Cryptotermes from the Bacteroidales ectosymbionts of these flagellates is in agreement with the virtual absence of anfH clones and the lack of detection of transcripts in K. flavicollis and I. marginipennis, two termites that harbor neither Devescovina nor Snyderella flagellates (Strassert et al., 2009, 2010). It is possible that the nifH homolog (Bact) most highly expressed in $K$. flavicollis originates from one of the two ectosymbionts of Joenia annectens, although it has to be considered that these ectosymbionts belong to a different lineage of Bacteroidales (Cluster IV; Strassert et al., 2010). Interestingly, the nifH homolog (Aarc) that is preferentially expressed in I. marginipennis is closely related to the nifH genes of Azoarcus species, which are known to fix nitrogen only as endosymbionts of grass roots (Hurek and Reinhold-Hurek, 2003). A 16S rRNAbased analysis of the gut microbiota of $I$. marginipennis conducted in our laboratory showed a large abundance of Rhodocyclales ( $>14 \%$ of all pyrotag sequences; $\mathrm{T}$ Köhler, unpublished results). It is

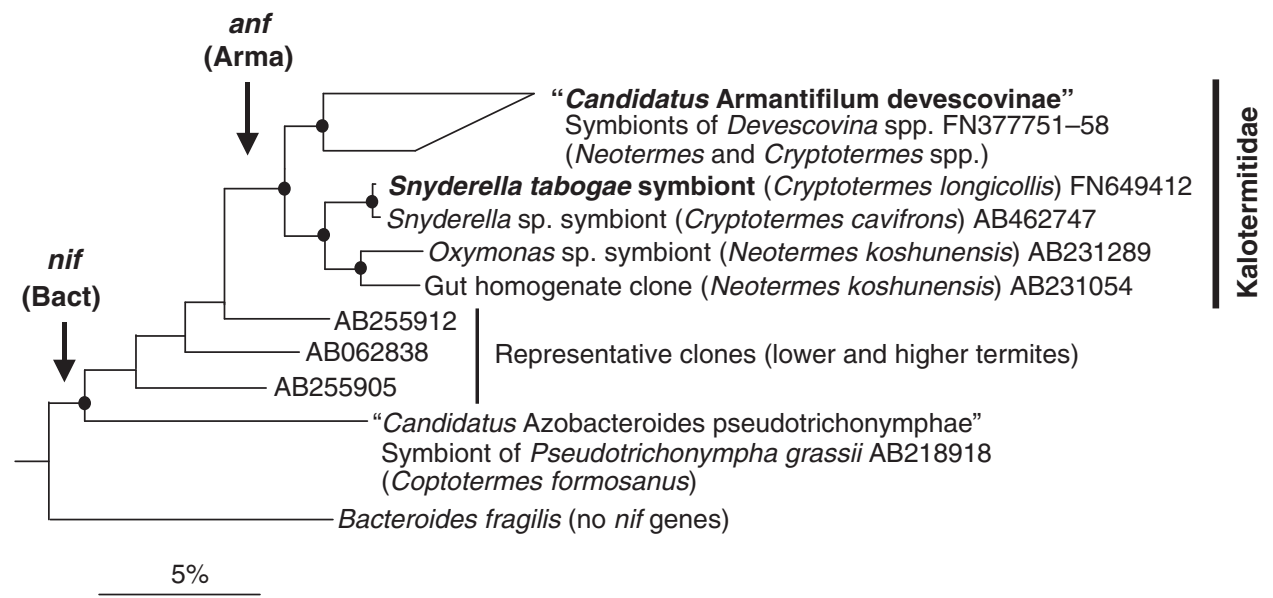

Figure 6 Phylogenetic tree of Bacteroidales Cluster-V, which consists exclusively of uncultivated bacteria from the gut of many termites. The 16S rRNA gene sequences of flagellate symbionts from dry-wood termites (Kalotermitidae) are shown in bold (Desai et al., 2010 and this study). Not all available sequences are shown (for more details, see Noda et al., 2009). Tree topology is based on maximum-likelihood analysis of 1273 unambiguously aligned nucleotide positions and was verified by maximum-parsimony analysis; nodes with high bootstrap support are marked $(\mathbf{0}>90 \%)$. The tree was rooted using other lineages of the Bacteroidetes as outgroup. The arrows indicate the hypothetical evolutionary events of nif and anf gene acquisition (see Discussion). 
possible that they represent another lineage of so-far unidentified flagellate symbionts with the capacity to fix nitrogen.

The isolation of the nitrogen-fixing spirochete T. azotonutricium and the presence of apparently spirochetal nifH homologs in all termites investigated have implicated spirochetes as potential nitrogen-fixing bacteria in termite guts (Lilburn et al., 2001). The results of our study document the preferential transcription of a spirochetal nifH gene (Cluster IIIb) in both $K$. flavicollis and I. marginipennis (Figure 2), thereby providing the first direct evidence for a key role of termite gut treponemes in $\mathrm{N}_{2}$ fixation. Termite gut treponemes possess several paralogs of nifH (Lilburn et al., 2001), but only the nifH genes in subgroup III-3b seem to be expressed in both termites. It remains to be investigated whether the capacity to fix nitrogen correlates with the ability of certain termite gut treponemes to form stable symbioses with flagellates (Noda et al., 2003).

The strong differences between the nitrogenfixing populations among the four species of dry-wood termites beg for an explanation. The rate of ethylene production in the acetylene reduction assay, which is directly proportional to the rate of nitrogen fixation (Hardy et al., 1973), allows the investigated termites to be separated into two groups: N. castaneus and I. marginipennis with high rates, and $C$. longicollis and $K$. flavicollis with low rates of nitrogen-fixing activity. Similar rates reported for Cryptotermes brevis (Breznak et al., 1973) and much higher rates in N. koshunensis than in C. domesticus (Ohkuma et al., 1999) suggest that these are genus-specific patterns. However, as $N$. castaneus and $C$. longicollis-the termite species harboring flagellates with anfH-expressing symbionts (Devescovina and Snyderella spp.)-differ strongly in their acetylene reduction activities, a direct link between the expression of a particular homolog and nitrogenase activity can be excluded. Rather, the expression patterns of the nifH homologs in N. castaneus and I. marginipennis did not change when the termites were fed nitrogen-free filter paper, even though acetylene reduction rates were markedly increased. Apparently, the intestinal community of these termites is well prepared to deal with different levels of nitrogen stress.

It has been shown that bacteria possessing both nif and anf genes preferentially express their anf paralogs in the absence of molybdenum cofactor (Masepohl and Klipp, 1996; Kessler et al., 1997; Braun et al., 1999). Based on their detailed study of nitrogenase activity, nifH gene expression and nif operon structure in $N$. koshunensis, Noda et al. (1999) had suggested that preferential expression of anfH in Kalotermitidae is related to the lack of molybdenum in sound wood, which may have favored the acquisition of a molybdenum-independent nitrogenase (that is, anfH) by their gut symbionts. As the anfH expression levels in $N$. koshunensis were not affected by the addition of molybdenum to the diet, they concluded that either anf gene expression is regulated in a different manner than in other bacteria or the symbiont possessing the anf genes may have lost the ability to produce the primary, molydenum-dependent nitrogenase (Noda et al., 1999). The transcript patterns obtained for $N$. castaneus and C. longicollis, and the preferential expression of anfH over nifH genes in the ectosymbionts of their major gut flagellates (this study), show that this phenomenon seems to be common in kalotermitids, and suggest that regulation of nif and anf gene expression by molybdenum in Cluster-V Bacteroidales may indeed differ from that in other prokaryotes.

As hydrogen has been shown to inhibit nitrogenases to various degrees (Guth and Burris, 1983), it seemed possible that differences in hydrogen partial pressure contribute to the particular nitrogenase expression pattern in the hindgut of a given termite species. However, the strong accumulation of hydrogen in K. flavicollis and I. marginipennis, and its virtual absence in $N$. castaneus and C. longicollis, correlate neither with the nitrogenase activity pattern nor the transcription of anfH genes, and transcription patterns did not change when $N$. castaneus and C. longicollis were incubated under external hydrogen. Rather, the hydrogen concentrations in the gut of the four termite species seem to reflect the types of flagellates present: Kalotermes and Incisitermes species harbor large hypermastigid flagellates (Joenia and Trichonympha, respectively), which are absent in Neotermes and Cryptotermes species (Yamin, 1979), and probably form the bulk of the hydrogen produced in the gut (Messer and Lee, 1989; Inoue et al., 2007). This is in agreement also with previous reports, where Reticulitermes and Zootermopsis species (harboring Trichonympha flagellates) showed high hydrogen partial pressures, and Cryptotermes secundus (lacking Trichonympha flagellates) showed only little accumulation of hydrogen (Ebert and Brune, 1997; Pester and Brune, 2007).

There is abundant evidence that the bacterial symbionts of most gut flagellates are specific for and even co-speciate with their respective hosts (for example, Stingl et al., 2005; Noda et al, 2006, 2007, 2009; Ikeda-Ohtsubo et al., 2007; Ohkuma et al., 2007; Ikeda-Ohtsubo and Brune, 2009; Desai et al., 2010; Strassert et al., 2010). The nitrogenfixing nature of the bacterial symbionts has been documented for at least two of these symbiotic pairs (Hongoh et al., 2008b and this study) and may indeed be the evolutionary driver for many of these associations. In view of the lack of correlation between the transcription patterns of nifH genes and other parameters that could potentially affect expression or activity of different nifH homologs, the species composition of the flagellate community emerges as the most likely determinant of the nitrogen-fixing populations prevailing in the 
hindgut of a given termite species. A preferential association of certain flagellates with nitrogen-fixing bacteria would give rise to a pattern of diazotrophs that reflects the species composition of the flagellate assemblage in a particular termite. Consequently, termites of the same genus, which often harbor closely related flagellates, should also share the same lineage of diazotrophs, resulting in phylogenetic clusters of nifH homologs specific for these taxa-a phenomenon that had been recognized already by Yamada et al. (2007). On the other hand, the assemblages of gut flagellates often differ substantially between different genera of termites within the same family. A prominent case is the family Kalotermitidae, where the differences in the distribution of Devescovina, Joenia and Trichonympha species may be responsible for the unique patterns of diazotrophic symbionts.

\section{Conflict of interest}

The authors declare no conflict of interest.

\section{Acknowledgements}

Mahesh S Desai received a doctoral fellowship from the International Max Planck Research School for Environmental, Cellular, and Molecular Microbiology. We are grateful to Rüdiger Plarre and Horst Hertel for providing termites, and Katja Meuser for technical assistance. We also thank Michael Pester and David K Ngugi for help with microsensor and GC measurements, Tim Köhler for sharing unpublished results, and Karen A Brune for comments on the manuscript.

\section{References}

Benemann JR. (1973). Nitrogen fixation in termites. Science 181: 164-165.

Braun S, Proctor L, Zani S, Mellon MT, Zehr JP. (1999). Molecular evidence for zooplankton-associated nitrogen-fixing anaerobes based on amplification of the nifH gene. FEMS Microbiol Ecol 28: 273-279.

Breznak JA, Brill WJ, Mertins JW, Coppel HC. (1973). Nitrogen fixation in termites. Nature 244: 577-580.

Breznak JA. (2000). Ecology of prokaryotic microbes in the guts of wood- and litter-feeding termites. In: Abe T, Bignell DE, Higashi M (eds). Termites: Evolution, Sociality, Symbiosis, Ecology. Kluwer Academic Publishers: Dordrecht, pp 209-231.

Brune A, Ohkuma M. (2011). Role of the termite gut microbiota in symbiotic digestion. In: Bignell DE, Roisin Y, Lo N (eds). Biology of Termites: a Modern Synthesis. Springer: Heidelberg, pp 439-475.

Brune A, Stingl U. (2005). Prokaryotic symbionts of termite gut flagellates: phylogenetic and metabolic implications of a tripartite symbiosis. In: Overmann J (ed). Molecular Basis of Symbiosis. Springer-Verlag: Berlin, pp 39-60.
Brune A. (2006). Symbiotic associations between termites and prokaryotes. In: Dworkin M, Falkow S, Rosenberg E, Schleifer K-H, Stackebrandt E (eds). The Prokaryotes Symbiotic Associations, Biotechnology, Applied Microbiology, 3rd edn, Vol. 1 Springer: New York, pp 439-474.

Cleveland LR. (1925). The ability of termites to live perhaps indefinitely on a diet of pure cellulose. Biol Bull 48: 289-293.

Dean DR, Jacobson MR. (1992). Biochemical genetics of nitrogenase. In: Stacy G, Burris RH, Evans HJ (eds). Biological Nitrogen Fixation. Chapman and Hall: New York, pp 763-834.

Desai MS, Strassert JFH, Meuser K, Hertel H, Ikeda-Ohtsubo W, Radek R, Brune A. (2010). Strict cospeciation of devescovinid flagellates and Bacteroidales ectosymbionts in the gut of dry-wood termites (Kalotermitidae). Environ Microbiol 12: 2120-2132.

Eady RR. (1996). Structure-function relationships of alternative nitrogenases. Chem Rev 96: 3013-3030.

Ebert A, Brune A. (1997). Hydrogen concentration profiles at the oxic-anoxic interface: a microsensor study of the hindgut of the wood-feeding lower termite Reticulitermes flavipes (Kollar). Appl Environ Microbiol 63: 4039-4046.

Graber JR, Leadbetter JR, Breznak JA. (2004). Description of Treponema azotonutricium sp. nov. and Treponema primitia sp. nov., the first spirochetes isolated from termite guts. Appl Environ Microbiol 70: 1315-1320.

Guth JH, Burris RH. (1983). Inhibition of nitrogenasecatalyzed $\mathrm{NH}_{3}$ formation by $\mathrm{H}_{2}$. Biochemistry 22: 5111-5122.

Hardy RWF, Burns RC, Holsten RD. (1973). Applications of the acetylene-ethylene assay for measurement of nitrogen fixation. Soil Biol Biochem 5: 47-81.

Henckel T, Friedrich M, Conrad R. (1999). Molecular analyse of the methane-oxidizing microbial community in rice field soil by targeting the genes of the $16 \mathrm{~S}$ rRNA, particulate methane monooxygenase, and methanol dehydrogenase. Appl Environ Microbiol 65: 1980-1990.

Hongoh Y, Ohkuma M. (2010). Termite gut flagellates and their methanogenic and eubacterial symbionts. In: Hackstein, JHP (ed). (Endo)symbiotic Methanogenic Archaea. Springer: Heidelberg, pp 55-79.

Hongoh Y, Sharma VK, Prakash T, Noda S, Taylor TD, Kudo $\mathrm{T}$ et al. (2008a). Complete genome of the uncultured Termite Group 1 bacteria in a single host protist cell. Proc Natl Acad Sci USA 105: 5555-5560.

Hongoh Y, Sharma VK, Prakash T, Noda S, Toh H, Taylor TD et al. (2008b). Genome of an endosymbiont coupling $\mathrm{N}_{2}$ fixation to cellulolysis within protist cells in termite gut. Science 322: 1108-1199.

Hurek T, Reinhold-Hurek B. (2003). Azoarcus sp. strain BH72 as a model for nitrogen-fixing grass endophytes. J Biotechnol 106: 169-178.

Ikeda-Ohtsubo W, Brune A. (2009). Cospeciation of termite gut flagellates and their bacterial endosymbionts: Trichonympha species and 'Candidatus Endomicrobium trichonymphae'. Mol Ecol 18: 332-342.

Ikeda-Ohtsubo W, Desai M, Stingl U, Brune A. (2007). Phylogenetic diversity of Endomicrobia and their specific affiliation with termite gut flagellates. Microbiology 153: 3458-3465.

Inoue J-I, Saita K, Kudo T, Ui S, Ohkuma M. (2007). Hydrogen production by termite-gut protists: characterization of iron hydrogenases of parabasalian symbionts of 
the termite Coptotermes formosanus. Eukaryot Cell 6: 1925-1932.

Kessler PS, McLarnan J, Leigh JA. (1997). Nitrogenase phylogeny and the molybdenum dependence of nitrogen fixation in Methanococcus maripaludis. J Bacteriol 179: 541-543.

Lilburn TG, Kim KS, Ostrom NE, Byzek KR, Leadbetter JR, Breznak JA. (2001). Nitrogen fixation by symbiotic and free-living spirochetes. Science 292: 2495-2498.

Lueders T, Manefield M, Friedrich MW. (2004). Enhanced sensitivity of DNA- and rRNA-based stable isotope probing by fractionation and quantitative analysis of isopycnic centrifugation gradients. Environ Microbiol 6: $73-78$.

Masepohl B, Klipp W. (1996). Organization and regulation of genes encoding the molybdenum nitrogenase and the alternative nitrogenase in Rhodobacter capsulatus. Arch Microbiol 165: 80-90.

Messer AC, Lee MJ. (1989). Effect of chemical treatments on methane emission by the hindgut microbiota in the termite Zootermopsis angusticollis. Microb Ecol 18: $275-284$.

Noda S, Hongoh Y, Sato T, Ohkuma M. (2009). Complex coevolutionary history of symbiotic Bacteroidales bacteria of various protists in the gut of termites. BMC Evol Biol 9: 158.

Noda S, Inoue $\mathrm{T}$, Hongoh $\mathrm{Y}$, Kawai $\mathrm{M}$, Nalepa CA, Vongkaluang $\mathrm{C}$ et al. (2006). Identification and characterization of ectosymbionts of distinct lineages in Bacteroidales attached to flagellated protists in the gut of termites and a wood-feeding cockroach. Environ Microbiol 8: 11-20.

Noda S, Kitade O, Inoue T, Kawai M, Kanuka M, Hiroshima K et al. (2007). Cospeciation in the triplex symbiosis of termite gut protists (Pseudotrichonympha spp.), their hosts, and their bacterial endosymbionts. Mol Ecol 16: 1257-1266.

Noda S, Ohkuma M, Kudo T. (2002). Nitrogen fixation genes expressed in the symbiotic microbial community in the gut of the termite Coptotermes formosanus. Microbes Environ 17: 139-143.

Noda S, Ohkuma M, Usami R, Horikoshi K, Kudo T. (1999). Culture-independent characterization of a gene responsible for nitrogen fixation in the symbiotic microbial community in the gut of the termite Neotermes koshunensis. Appl Environ Microbiol 65: 4935-4942.

Noda S, Ohkuma M, Yamada A, Hongoh Y, Kudo T. (2003). Phylogenetic position and in situ identification of ectosymbiotic spirochetes on protists in the termite gut. Appl Environ Microbiol 69: 625-633.

Ohkuma M, Brune A. (2011). Diversity, structure, and evolution of the termite gut microbial community. In: Bignell DE, Roisin Y, Lo N (eds). Biology of Termites: a Modern Synthesis. Springer: Dordrecht, pp. 413-438.

Ohkuma M, Noda S, Usami K, Horikoshi, Kudo T. (1996). Diversity of nitrogen fixation genes in the symbiotic intestinal microflora of the termite Reticulitermes speratus. Appl Environ Microbiol 62: 2747-2752.

Ohkuma M, Noda S, Hongoh Y, Kudo T. (2002). Diverse bacteria related to the Bacteroides subgroup of the
CFB phylum within the gut symbiotic communities of various termites. Biosci Biotechnol Biochem 66: 78-84.

Ohkuma M, Noda S, Kudo T. (1999). Phylogenetic diversity of nitrogen fixation genes in the symbiotic microbial community in the gut of diverse termites. Appl Environ Microbiol 65: 4926-4934.

Ohkuma M, Sato T, Noda S, Ui S, Kudo T, Hongoh Y. (2007). The candidate phylum 'Termite Group 1' of bacteria: phylogenetic diversity, distribution, and endosymbiont members of various gut flagellated protists. FEMS Microbiol Ecol 60: 467-476.

Pester M, Brune A. (2006). Expression profiles of fhs (FTHFS) genes support the hypothesis that spirochaetes dominate reductive acetogenesis in the hindgut of lower termites. Environ Microbiol 8: 1261-1270.

Pester M, Brune A. (2007). Hydrogen is the central free intermediate during lignocellulose degradation by termite gut symbionts. ISME J 1: 551-565.

Sicking C, Brusch M, Lindackers A, Riedel K-U, Schubert $\mathrm{B}$, Isakovic $\mathrm{N}$ et al. (2005). Identification of two new genes involved in diazotrophic growth via the alternative Fe-only nitrogenase in the phototrophic purple bacterium Rhodobacter capsulatus. J Bacteriol 187: 92-98.

Stingl U, Radek R, Yang H, Brune A. (2005). 'Endomicrobia': cytoplasmic symbionts of termite gut protozoa form a separate phylum of prokaryotes. Appl Environ Microbiol 71: 1473-1479.

Strassert JFH, Desai MS, Brune A, Radek R. (2009). The true diversity of devescovinid flagellates in the termite Incisitermes marginipennis. Protist 160: $522-535$.

Strassert JFH, Desai MS, Radek R, Brune A. (2010). Identification and localization of multiple bacterial symbionts in the termite gut flagellate Joenia annectens. Microbiology 156: 2068-2079.

Tayasu I, Inoue T, Miller LR, Sugimoto A, Takeichi S, Abe T. (1998). Confirmation of soil-feeding termites (Isoptera; Termitidae; Termitinae) in Australia using stable isotope ratios. Funct Ecol 12: 536-542.

Warnecke F, Luginbühl P, Ivanova N, Ghassemian M, Richardson TH, Stege JT et al. (2007). Metagenomic and functional analysis of hindgut microbiota of a wood-feeding higher termite. Nature 450: 560-565.

Yamada $\mathrm{A}$, Inoue $\mathrm{T}$, Noda $\mathrm{S}$, Hongoh $\mathrm{Y}$, Ohkuma $\mathrm{M}$. (2007). Evolutionary trend of phylogenetic diversity of nitrogen fixation genes in the gut community of wood-feeding termites. Mol Ecol 16: 3768-3777.

Yamin MA. (1979). Flagellates of the orders Trichomonadida Kirby, Oxymonadida Grassé, and Hypermastigida Grassi and Foà reported from lower termites (Isoptera families Mastotermitidae, Kalotermitidae, Hodotermitidae, Termopsidae, Rhinotermitidae, and Serritermitidae) and from the wood-feeding roach Cryptocercus (Dictyoptera: Cryptocercidae). Sociobiology 4: 1-119.

Zehr JP, Jenkins BD, Short SM, Steward GF. (2003). Nitrogenase gene diversity and microbial community structure: a cross-system comparison. Environ Microbiol 5: 539-554. 